\title{
Carta pela valorização das comissões parlamentares de inquérito
}

\author{
Eduardo Kroeff Machado Carrion*
}

\section{NOTA EXPLICATIVA}

$O$ documento abaixo transcrito foi entregue ao Presidente da República, em reunião realizada no Palácio do Planalto em 2 de agosto 2006, por comissão de dez membros, entre os quais quatro (4) ex-presidentes do Conselho Federal da Ordem dos Advogados do Brasil, constituida por iniciativa da Secretaria de Relações Institucionais da Presidência da República. A minuta do texto, que, para a conformação final do documento, recebeu importantes contribuições dos demais membros da comissão, foi de minha autoria, tendo assumido, ao mesmo tempo, a condição de relator da mesma. Na sessão ordinária do dia 30 de outubro de 2006, o Pleno do
Conselho Federal da Ordem dos Advogados do Brasil proferiu, por unanimidade, decisão "acolhendo os termos do voto do eminente Conselheiro Federal Alberto Zacharias Toron, no sentido de que a $O A B$ se some à proposta pela 'atualização e modernização da normatividade infraconstitucional com relação ao funcionamento das Comissões Parlamentares de Inquérito', propondo, como alvitrado na 'Carta Pela Valorização das Comissões Parlamentares de Inquérito', que, "respeitadas as competências constitucionais dos Poderes da República, a matéria seja discutida pelas entidades da sociedade civil, pelos cidadãos em geral e seus

\footnotetext{
* Ex-diretor e professor titular de Direito Constitucional da Faculdade de Direito da UFRGS. Leciona, atualmente, no Curso de Especialização em Direito Constitucional e na Faculdade de Direito da Fundação Escola Superior do Ministério Público do Rio Grande do Sul (FMP), bem como no Curso Oficial de Preparação à Magistratura do Trabalho da Fundação Escola da Magistratura do Trabalho/RS (FEMARGS).
} 
representantes políticos" (Ofício COP/213/2006 dirigido, em 20 de novembro de 2006, pelo Presidente do Conselho Federal da $O A B, D r$. Roberto Antonio Busato, ao Ministro de Estado Chefe da Secretaria de Relações Institucionais, Dr. Tarso Genro). Em seu voto, o Conselheiro Federal Alberto Zacharias Toron, designado relator, entre outras observações, salienta: "De minha parte penso que o documento apresentado para análise deste E. Conselho é dessas peças que não merecem nenhum retoque ou acréscimo. Mais: entusiasticamente a subscreveria e, por igual, conclamaria este Conselho a fazê-lo". Acrescenta ainda: "O quanto registrado, por si só, já recomendaria encampar a idéia consolidada no documento em exame, qual seja, sobre a necessidade de atualização e modernização da legislação que regula o funcionamento das CPIs". E conclui: "Por estas e muitas outras razões que poderiam ser alinhavadas, opino no sentido de que a $O A B$ se some à proposta pela 'atualização e modernização da normatividade infraconstitucional com relação ao funcionamento das Comissões Parlamentares de Inquérito', propondo, como alvitrado no documento, que, respeitadas as competencias constitucionais dos Poderes da República, a matéria seja discutida pelas entidades da sociedade civil, pelos cidadãos em geral e seus representantes políticos". EKMC

\section{A CARTA}

Excelentíssimo Senhor Luiz Inácio Lula da Silva

Digníssimo Presidente da República Federativa do Brasil

Assunto: Carta Pela Valorização das Comissões Parlamentares de Inquérito

Excelentíssimo Senhor Presidente da República,

As Comissões Parlamentares de Inquérito (CPIs), previstas no $\S 3^{\circ}$ do artigo 58 da Constituição, são um instrumento importante do controle parlamentar da Administração Pública. Embora a legislação seja uma incumbência essencial do Poder Legislativo, o controle torna-se crescentemente uma de suas principais atribuições, favorecendo igualmente um melhor equilíbrio e colaboração entre os Poderes, a responsabilização do Executivo e a transparência da Administração Pública. Podendo ser criadas "pela Câmara dos Deputados e pelo Senado Federal, em conjunto ou separadamente, mediante requerimento de um terço de seus membros", as Comissões Parlamentares de Inquérito, sem deixarem de ser uma emanação e representação do órgão, expressam também o poder e o papel das minorias parlamentares, eventualmente da própria oposição, que exercem uma função indispensável na cena política democrática.

A origem histórica das Comissões Parlamentares de Inquérito remonta pelo menos ao século XVII na Inglaterra, alguns apontando mesmo suas raízes no século 
XIV. Desde então, os mais diversos regimes políticos democráticos recepcionaram, sob diferentes denominações e distintas modalidades, as Comissões Parlamentares de Inquérito em suas Constituições. Revestem-se elas, assim, de dignidade e importância democráticas, tal como tem ensinado a prática histórica.

No Brasil, a Constituição de 1934 foi a primeira a expressamente prever as Comissões Parlamentares de Inquérito. A partir de então, salvo o interregno das experiências autoritárias, o instituto tem sido aperfeiçoado. A Constituição de 1988, significando novos tempos e reconhecendo sua importância, ampliou o papel e as atribuições das Comissões Parlamentares de Inquérito, em correspondência, aliás, com a ampliação do papel e das atribuições do Congresso Nacional. Passaram, assim, a ter "poderes de investigação próprios das autoridades judiciais, além de outros previstos nos regimentos das respectivas Casas", devendo, entretanto, ser sempre respeitada a competência exclusiva do Poder Judiciário para a prática de determinados atos, a denominada "cláusula de reserva jurisdicional". Com o novo regime constitucional, sucessivas Comissões Parlamentares de Inquérito foram instaladas, nas mais diversas áreas da atividade social, a denotar sua presença cada vez mais marcante na vida política nacional. A título de exemplo, cabe lembrar a CPI do Caso Collor (1992), a CPI do Orçamento (1993), a CPI dos Precatórios (1997), a CPI dos Bancos (1999), a CPI do Judiciário (1999), a CPI do Narcotráfico (1999/2000), a CPI do Roubo de Cargas (2000/2002), sem referir as mais recentes.

Reconhecida e ressaltada a importância das Comissões Parlamentares de Inquérito, convém sempre lembrar que devem elas, no exercício de suas atribuições, submeter-se ao império da lei e, em especial, da
Constituição. Por isso mesmo, já de há muito e reiteradamente, tem agido, quando provocado, o Supremo Tribunal Federal (STF) no sentido de definir as faculdades e limites constitucionais das Comissões Parlamentares de Inquérito. Nesse particular, cabe destacar o Acórdão prolatado pelo Plenário do STF no MS n ${ }^{\circ}$ 23.452-1-RJ, relator o Ministro Celso de Mello, paradigmático em grande parte.

Antes de tudo, hão de pautar-se pelo princípio da finalidade. No caso, significa uma investigação para "apuração de fato determinado". Isso não impede que possam, as Comissões Parlamentares de Inquérito, no decorrer de suas investigações, debruçar-se, nem que seja sob a forma de aditamento, sobre fatos novos que guardem conexão ou íntima ligação com os fatos apurados. Mas não podem, desviar o foco e mudar o rumo das investigações, com o risco ainda de perderse no emaranhado de temas trazidos a exame. Da mesma forma, embora possam proporcionar momento de exercício agudo da disputa política, não podem transformarse em elemento rasteiro da luta política conjuntural, contrariando seus altos objetivos institucionais, tal como se deduz do texto constitucional.

Destaque especial deve ser dado aos direitos do cidadão. Inadmissível que as Comissões Parlamentares de Inquérito se transformem em instrumento de abusos e devassas contra particulares, atentando contra direitos constitucionais, máxime quando inexistente nexo causal com os fatos apurados. Muitas vezes, a intimidade das pessoas e das famílias, assim como os negócios particulares do cidadão são levados a público, sem respeito a quaisquer limites. Quando se fala em direitos do cidadão, fala-se igualmente em direitos de defesa do cidadão e, portanto, em prerrogativas de seus advogados, tal como, 
aliás, vem sendo reiteradamente reconhecido pelo STF.

Tão ou mais importante do que o pedido de responsabilização civil e criminal dos infratores, tal como previsto no texto constitucional, talvez sejam os resultados e as propostas de aperfeiçoamento das instituições e de medidas, administrativas e legislativas, de prevenção com relação a eventuais futuras infrações. Nesse sentido, importante que os relatórios finais das Comissões Parlamentares de Inquérito concluam-se sempre por propostas legislativas, quando isso for necessário ou conveniente para o resguardo do interesse público.

Seguramente, obedecidos parâmetros mínimos em sua atuação, as Comissões Parlamentares de Inquérito poderão cada vez mais contribuir para o aperfeiçoamento das instituições e para o processo democrático, legitimando-se crescentemente junto à sociedade e à cidadania.

Atualmente, regem, no plano infraconstitucional, o funcionamento e a atuação das Comissões Parlamentares de Inquérito, a Lei $\mathrm{n}^{\circ} 1.579$ de $18 / 03 / 1952$, alterada pela Lei $n^{\circ} 10.679$ de $23 / 05 / 2003$, a Lei $n^{\circ} 10.001$ de $04 / 09 / 2000$, bem como as normas regimentais: Regimento Interno da Câmara dos Deputados, Regimento Interno do Senado Federal e Regimento Comum do Congresso Nacional.

Desde 1952, quando da edição da Lei $\mathrm{n}^{\circ} 1.579$, já houve uma rica experiência acumulada com relação às Comissões Parlamentares de Inquérito, que aponta para a oportunidade de um aperfeiçoamento da legislação vigente. Aliás, por iniciativa da atual Presidência do STF, está se consolidando a jurisprudência de nosso Tribunal Constitucional com referência ao tema.
A atualização e modernização da normatividade infraconstitucional com relação ao funcionamento das Comissões Parlamentares de Inquérito, sem que isso possa significar qualquer limitação ao seu importante papel institucional na vida democrática, podem representar um fator de progresso, evitando ademais conflitos desnecessários entre os Poderes da República. Respeitando as competências constitucionais dos Poderes da República, do Executivo, que poderá tomar a iniciativa de um projeto de lei e que terá ainda a responsabilidade da sanção, do Legislativo, a quem cabe finalmente discutir e deliberar, seria de todo conveniente que o debate se tornasse público, trazendo assim a colaboração dos mais diversos segmentos e setores.

Vossa Excelência, na condição de chefe do Poder Executivo da República Federativa do Brasil, poderia propiciar, em conjunto e harmonia com as Chefias dos demais poderes, iniciativas neste sentido.

Esse, Excelentíssimo Senhor Presidente da República, nosso entendimento sobre a matéria e nossa despretensiosa colaboração para o aperfeiçoamento das instituições republicanas e democráticas.

Atenciosamente,

Américo Lacombe

Dalmo de Abreu Dallari

Eduardo Kroeff Machado Carrion

Eduardo Seabra Fagundes

Hermann Assis Baeta

Luis Carlos Madeira

Marcelo Lavenère Machado

Ovídio Rocha Barros Sandoval

Reginaldo Oscar de Castro

Roberto de Figueiredo Caldas 